\title{
Effects of Eryngium caucasicum extract on Testosterone, inflammation and oxidative status of Nicotinamide-Streptozotocin induced Type-2 Diabetes in male rats
}

\author{
Masood Afshari, ${ }^{a}$ Ali Reza Malayeri, ${ }^{b}$ and Majid Mohammadshahic*
}

aDepartment of Nutrition, Jundishapour University of Medical Sciences, Ahvaz, Iran.

${ }^{b}$ Medical Plant Research Center, Jundishapour University of Medical Sciences. Ahvaz, Iran.

Department of Nutrition, Hyperlipidemia Research Center, Jundishapour University of Medical Sciences. Ahvaz, Iran.

*Correspondence to Majid Mohammadshahi (email: shahi334@gmail.com).

(Submitted: 04 December 2018 - Revised version received: 27 December 2018 - Accepted: 23 January 2018 - Published online: 26 April 2019)

\begin{abstract}
Objective Regarding the unfavorable side effects of anti-diabetic drugs including peripheral edema, gastrointestinal discomfort and hypoglycemia, using medicinal plants due to their useful contents such as flavonoids, alkaloids, glycopeptides, terpenoides, phenolic compounds and other constituents with antioxidant and anti-inflammatory effects, is encouraged in treatment of diabetes mellitus. Thus, the hypothesis was that Eryngium caucasicum extract will decrease inflammation and oxidative stress in nicotinamide-streptozotocin induced type 2 diabetes mellitus model in Wistar rats.

Methods In this study, sixty adult male Wistar rats (150-250 g) were randomly allocated into six groups $(n=10)$ including: (1) healthy control, (2) diabetic control, (3) diabetic rats which received Sitagliptine, (4-6) diabetic rats which received 100, $200 \mathrm{and} 300 \mathrm{mg} / \mathrm{kg}$ of E. caucasicum extract oral gavages for 30 days. Eventually, total antioxidant capacity, vitamin B12, malondyaldehyde, interleukin-6, high sensitive C-reactive protein and testosterone serum levels were measured.

Results Administration of E. caucasicum in type 2 diabetes mellitus animal model did not change serum vitamin B12 and animal weight compared with control groups. Total antioxidant capacity and malondyaldehyde improved in all doses of E. caucasicum; in the highest doses, the total antioxidant capacity was higher than sitagliptine group. Interleukin- 6 and high sensitive C-reactive protein both decreased in all doses of E. caucasicum. Administration of E. caucasicum extract improved testosterone serum level only in highest dose of E. caucasicum extract. Since the highest dose showed the highest antioxidant and anti-inflammatory effects; dose-responses of antioxidant and antiinflammatory effects are suggested.

Conclusion In conclusion, we showed that administration of E. caucasicum in T2DM animal model has antioxidant and anti-inflammatory effects. However, in future studies other dose-escalating intervention must be performed. Also toxicity in diabetes must be elucidated in future studies.

Keywords Eryngium caucasicum extract, testosterone, inflammation, oxidative status
\end{abstract}

\section{Introduction}

Diabetes mellitus (DM) is a multi-systemic endocrine disorder with constant hyperglycemia due to either absolute or relative defective insulin secretion, insulin resistance or both. ${ }^{1}$ The prevalence of DM is rising all over the world in both developed and developing countries. About $90 \%$ of all diabetic cases are type 2 diabetes mellitus (T2DM). According to WHO, the global prevalence of T2DM will increase to 366 million in 2030 . $^{2} \mathrm{DM}$ is reported to devote $7-13 \%$ of the healthcare budget of worldwide and a major challenge to healthcare systems. $^{3}$ Long-term hyperglycemia is contributed to many chronic end-organ microvascular and macrovascular damages in the eyes, kidneys and the brain. Also, T2DM-related cardiovascular diseases can increase morbidity and mortality among patients with DM. ${ }^{4}$ Mild to moderate proinflammatory status has been implicated in DM. This setting is proposed as a link between disease progression and its complications. Mounting evidence showed increased cytokine level and immune cell infiltration in pancreatic cells in DM. ${ }^{5}$ In addition epidemiological studies support this data that inflammatory markers like interleukin-6 (IL-6) are associated with development of DM. ${ }^{6}$ IL- 6 reported as a mediator which act between insulin-sensitive tissues, and pancreatic islets to adapt to changes in insulin demand. ${ }^{7}$ Prolonged hyperglycemia along with proinflammatory settings, disturbs normal balance of oxidant-antioxidant capacity within the cells, which results in oxidative stress and injury, beta cell death and/or de-differentiation to glucagon-producing cells. ${ }^{8}$ Despite current advances in anti-diabetic drugs, their use is complicated due to the unfavorable side effects like peripheral edema, gastrointestinal discomfort and hypoglycemia. ${ }^{9}$ Recently the use of medicinal plants for the sufferers of DM is encouraged because of their perceived effectiveness, fewer side effects and relatively low costs. It has been estimated that more than 1000 medicinal plants are used as anti-diabetic remedies. ${ }^{10}$ Several phytoconstituents in herbal remedies reported as useful agents against DM. These include flavonoids, alkaloids, glycopeptides, terpenoides and phenolic compounds and other constituents which show fasting blood glucose (FBS) lowering effects. ${ }^{11}$

The Eryngium genus, as the largest genus of the family Apiaceae, consists of more than 250 flowering species all over the world. ${ }^{12}$ Eryngium caucasicum which is known as Eryngo has been cultivated in middle-east countries like Iran and Turkey. ${ }^{13}$ In northern Iran it has been widely used as different foodstuffs like pickles. Apiaceae have several therapeutic uses as diuretic, stone inhibitor, expectorant and antinociceptive. ${ }^{13}$ Other uses in Turkish folk medicine are against various inflammatory disorders, edema, sinusitis, urinary infections or inflammations etc. ${ }^{14}$ In essence, E. caucasicum reported to 
have numerous therapeutic properties comprising strengthening generative power, diuretic, lenitive and appetizer. ${ }^{15}$ Antioxidant and potent free radical scavenging activity of E. caucasicum Trautv leaves have been reported. In addition it is reported to have antihypoxic and reno-protective effects. ${ }^{16}$ Anti-inflammatory activities of Eryngium species growing in Turkey has been evaluated in vivo. Aerial parts and roots reported to possess many activities. ${ }^{17}$ Several bioactive compounds, mainly phenolic compounds and terpenoids have been purified from Eryngium species which include triterpenoid saponins, flavonoids, coumarins and acetylenes. ${ }^{18}$

In this study we aimed to evaluate anti-inflammatory and anti-oxidative potential and possible effects of E. caucasicum extract on testosterone in nicotinamide-streptozotocin (NA-STZ) induced T2DM model in rats.

\section{Materials and Methods}

\section{Plant Material and Extract Preparation}

Fresh leaves of E. caucasicum were obtained from Mazandaran province, Iran and authenticated scientifically by the Botany Department of Ahvaz Jundishapur University of Medical Sciences (AJUMS), Ahvaz, Iran. Voucher specimens are deposited in the Herbarium Department of Biology, University of Mazandaran, Iran (No 1442). The plant leaves were desiccated in shade and then crushed and powdered by grinder.

A total of $300 \mathrm{~g}$ of the powder of E. caucasicum leaves were soaked in $1200 \mathrm{ml}$ of an ethanol and distilled water mixture (70-30) and stocked for $72 \mathrm{~h}$ at room temperature. The mixture filtered through Whatman filter papers (No. 1) and then centrifuged at $3500 \mathrm{rpm}$ for $20 \mathrm{~min}$. Condensation conducted by rotary evaporator. Finally, supernatant was dried at $37^{\circ} \mathrm{C}$, and the obtained semisolid mass was stocked at $4^{\circ} \mathrm{C}$ until injection.

\section{Experimental Animals}

Sixty adult male Wistar rats (150-250 g) were purchased from animal house of AJUMS. All experimental animals were kept in standard cages under approved conditions for animal procedures (temperature $22 \pm 2^{\circ} \mathrm{C}$ with a $12-12 \mathrm{~h}$ light-dark cycle). Experimental animals were allowed to access normal commercial chow and tap water. Maintenance and care of experimental animals complied with the National Research Council of the National Academic.

\section{Induction of Type 2 Diabetes Mellitus}

In this study, type 2 diabetes was induced by intraperitoneal (IP) injection of NA ( $120 \mathrm{mg} / \mathrm{kg}$ body weight in normal saline) (Sigma-Aldrich, USA) 15 min before a single dose of STZ (55 mg/kg body weight; dissolved in citrate buffer (0.1M), $\mathrm{pH}$ 4.5) (Sigma-Aldrich, USA). Animals suffer from fasting for $8-12 \mathrm{~h}$ before T2DM induction. The development of T2DM was evaluated by FBS in animals. FBS was measured before and $72 \mathrm{~h}$ after injection to confirm diabetes induction. FBS more than $250 \mathrm{mg} / \mathrm{dl}$ were considered diabetic. Only those animals with confirmed diabetes were used for following experiments.

\section{Experimental Protocol}

After 2 weeks of adaptation, rats were divided into the following groups ( $n=10$ in each group):
- Group 1: Six healthy control $(0.5 \mathrm{ml} / \mathrm{kg}$ normal saline oral gavage).

- Group 2: Six diabetic control group $(0.5 \mathrm{ml} / \mathrm{kg}$ normal saline oral gavage).

- Group 3: Six T2DM + sitagliptine $(10 \mathrm{mg} / \mathrm{kg}$ oral gavage)

- Group 4: Six T2DM + E. caucasicum extract (100 mg/kg oral gavage).

- Group 5: Six T2DM + E. caucasicum extract (200 mg/kg oral gavage).

- Group 6: Six T2DM + E. caucasicum extract (300 mg/kg oral gavage).

All groups treated once a day for 28 sequential days with sitagliptine or E. caucasicum extract. Sitagliptine was dissolved in distilled water. Body weight was recorded weekly during the experiment. At $24 \mathrm{~h}$ after the last injection, mice were kept fasted overnight. All animals were killed under ether anesthesia. Blood samples were obtained by heart puncture. Samples were poured into centrifuge tubes and centrifuged at 3500 $\mathrm{rpm}$ for $20 \mathrm{~min}$. Serum samples were refrigerated at $-70^{\circ} \mathrm{C}$ refrigerator until biochemical analysis.

\section{Biochemical Assessments}

Fasting blood glucose were assessed by an Elegance glucometer (CT-X10, Convergent Technologies, Germany) using the lateral tail vein of the animals on the first and last days of the experiment.

Total antioxidant capacity (TAC) was assessed by spectrophotometer and commercial kits (RANDOX, England). Also malondyaldehyde (MDA) serum level was assessed through thiobarbiturate method. Following factors were assessed by ELISA method: IL-6 (BehpadTeb, Iran), testosterone (MonoBiol, USA). Circulating high sensitive C-reactive protein (hs-CRP) was evaluated by turbidimetry method (BioSystem, Barcelona, Spain). Serum vitamin B12 was evaluated by radioimmunoassay using gamma counter.

\section{Statistical Analysis}

All data were expressed as mean \pm standard error of mean (SEM). Results were analyzed by one-way analysis of variance (ANOVA), followed by post-hoc test [least significant difference (LSD)]. All Statistical analysis were performed by SPSS Statistics V. 17.01 (SPSS Inc., Chicago, USA).

\section{Results}

\section{Effects of Hydro-alcoholic Extract E. caucasicum on Body Weight, FBS and Serum Vitamin B12}

Our results indicated that STZ-NA-induced diabetes did not change body weight in diabetic control group $(P$-value $=$ 0.634). Administration of sitagliptin in diabetic rats decreased body weight significantly compared with diabetic control $(P$-value $=0.008)$ and healthy control group $(P$-value $=0.028)$. However, E. caucasicum administration in $300 \mathrm{mg} / \mathrm{kg}$ increased body weight significantly compared with Sitagliptin group $(P$-value $=0.002)$. Induction of diabetes significantly increased FBS in diabetic rats compared with healthy control group $(P$-value $=0.009)$. Sitagliptin also decreased FBS in diabetic rats significantly $(P$-value $=0.004)$. Furthermore, only high doses including 200 and $300 \mathrm{mg} / \mathrm{kg}$ decreased FBS in 
distinct period $(P$-value $=0.038$ and 0.004 respectively) . Although a dose-dependent manner reported in reducing FBS following increasing doses of E. caucasicum extract as outlined in Table 1. Furthermore, serum vitamin B12 revealed no significant changes in any of experimental groups during intervention period.

\section{Effects of Hydro-alcoholic Extract E. Caucasicum on Inflammatory Biomarkers}

Induction of diabetes using STZ-NA increased serum hs-CRP in diabetic control group compared with healthy control group. Sitagliptine significantly lowered hs-CRP serum level $(P$-value $=$ $0.001)$. Treatment with plant extract also lowered serum hs-CRP level in dose-dependent manner as shown in Table 2.

Interleukin- 6 serum level increased significantly after diabetes induction. Administration of Sitagliptine significantly improved IL-6 serum level. E. caucasicum extract also lowered IL-6 in a dose-dependent manner as depicted in Table 2.

\section{Effects of Hydro-alcoholic Extract E. caucasicum on TAC and MDA}

Malondyaldehyde serum level increased after induction of diabetes in diabetic control group. Although sitagliptine improved MDA serum level, did not improve it as efficiently as E. caucasicum extract. Administration of herb extract lowered serum level of MDA in a dose-dependent manner. MDA also in 200 and $300 \mathrm{mg} / \mathrm{kg}$ were significantly lower than sitagliptine $(P$-value $=0.023$ and 0.006 respectively $)$.

Total antioxidant capacity also decreased after T2DM induction. However, administration of sitagliptine improved TAC significantly $(P$-value $=0.030)$. All three doses of E. caucasicum extract improved TAC but was not as efficient as sitagliptine ( $P$-value for all doses $<0.001)$.

\section{Effects of Hydro-alcoholic Extract E. Caucasicum on Serum Testosterone Level}

As shown in Figure 1, all experimental diabetic groups showed lower testosterone serum level compared with healthy control group. Sitagliptine treatment did not improve testosterone serum level in diabetic rats. But $300 \mathrm{mg} / \mathrm{kg}$ of plant extract increased serum testosterone level significantly. This observation showed dose-dependent effects of E. caucasicum extract as shown in figure.

\section{Discussion}

The results of this study indicate that E. caucasicum exerted beneficial effects on increasing TAC, decreasing MDA, IL-6, hs-CRP and improving testosterone serum level without any changes on serum vitamin B12 and animals' body weights in STZ-NA rats, T2DM animal model compared with control groups. TAC improved in all doses of E. caucasicum although it was higher than sitagliptine group in the highest dose. MDA also improved in all groups after administration of E. caucasicum. All of these observations showed the antioxidant effects of E. caucasicum in diabetic rats.

Mounting evidence has pointed out several pharmacological effects of the genus Eryngium including antioxidant, anti-hypoxic and free radical scavenging effects. ${ }^{19}$ Similarly, Wang et al. ${ }^{18}$ and Mirjana et al. ${ }^{20}$ reported the same findings. Antioxidant activity of Eryngium genius contributed to its aerial parts, extracted oil, roots, fruits etc. ${ }^{21}$ The antioxidant effects of Eryngium extracts were evaluated using 2,2-diphenyl-1-1-picrylhydrazil and ferric reducing antioxidant power assays which showed significant antioxidant activities. $^{22}$ In essence, E. caucasicum fractions demonstrated different levels of antioxidant and anti-hemolytic activities in different models. Hypoxia mediates the production of nitric oxide (NO) and its radicals and also ROS. ${ }^{13} \mathrm{NO}$ reported to modulate iron catalyzed oxidation reactions such as Fenton reaction, which generates potent oxidants such as the hydroxyl radical $\left(\mathrm{OH}^{*}\right)$. NO scavenging may suggest likelihood to counteract hypoxia. ${ }^{23}$ The mechanisms by which NO may block lipid peroxidation needed to be clarified, however, one plausible mechanism linked to the potential of NO to cease propagation of lipid peroxidation reactions. ${ }^{24}$ Eryngium

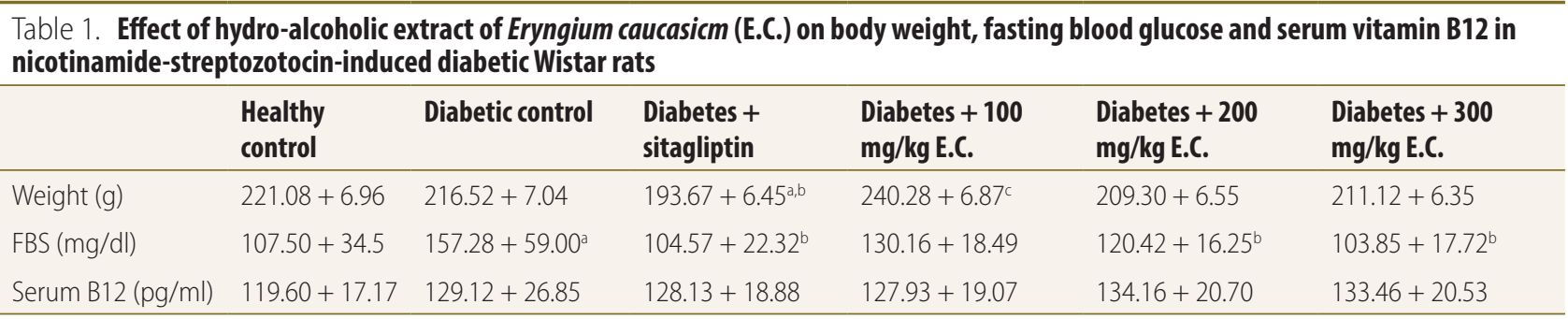

${ }^{a} p<0.05$ compared with the control group. ${ }^{b} p<0.05$ compared with the diabetic control group. ${ }^{c} p<0.05$ compared with the diabetic animals received Sitagliptin. Results are expressed as mean + SEM (standard error of mean), one-way ANOVA and post-hoc LSD test. E.C.: Eryngium caucasicm; FBS: fasting blood glucose.

Table 2. Effect of hydro-alcoholic extract of Eryngium caucasicm (E.C.) on inflammatory and oxidative stress markers in nicotinamide-streptozotocin-induced diabetic Wistar rats

\begin{tabular}{lllllll}
\hline & Healthy control & Diabetic control & $\begin{array}{l}\text { Diabetes }+ \\
\text { sitagliptin }\end{array}$ & $\begin{array}{l}\text { Diabetes + 100 } \\
\mathbf{m g} / \mathbf{k g ~ E . C .}\end{array}$ & $\begin{array}{l}\text { Diabetes + 200 } \\
\mathbf{m g} / \mathbf{k g ~ E . C .}\end{array}$ & $\begin{array}{l}\text { Diabetes + 300 } \\
\mathbf{m g} / \mathbf{k g ~ E . C .}\end{array}$ \\
\hline TAC $(\mu \mathrm{mol} / \mathrm{l})$ & $0.931+0.135$ & $0.371+0.101^{\mathrm{a}}$ & $0.611+0.348^{\mathrm{a}, \mathrm{b}}$ & $0.776+0.127^{\mathrm{b}}$ & $0.814+0.181^{\mathrm{b}}$ & $0.872+0.172^{\mathrm{b}, \mathrm{c}}$ \\
$\mathrm{MDA}(\mu \mathrm{mol} / \mathrm{l})$ & $1.57+0.65$ & $3.98+1.02^{\mathrm{a}}$ & $2.88+0.83^{\mathrm{a}, \mathrm{b}}$ & $1.97+0.71^{\mathrm{b}}$ & $1.83+0.96^{\mathrm{b}}$ & $1.56+0.71^{\mathrm{b}}$ \\
II-6 $(\mathrm{pg} / \mathrm{ml})$ & $66.68+11.80$ & $124.59+32.09^{\mathrm{a}}$ & $89.90+12.64^{\mathrm{a}, \mathrm{b}}$ & $101.47+6.16^{\mathrm{a}, \mathrm{b}}$ & $101.80+10.84^{\mathrm{a}, \mathrm{b}}$ & $90.25+11.45^{\mathrm{a}, \mathrm{b}}$ \\
$\mathrm{hs}-\mathrm{CRP}(\mu \mathrm{mol} / \mathrm{l})$ & $7047+1.29$ & $14.62+2.49^{\mathrm{a}}$ & $10.14+2.60^{\mathrm{a}, \mathrm{b}}$ & $11.24+2.79^{\mathrm{a}, \mathrm{b}}$ & $10.77+1.88^{\mathrm{a}, \mathrm{b}}$ & $8.94+1.96^{\mathrm{b}}$ \\
\hline
\end{tabular}

${ }^{a} p<0.05$ compared with the control group. ${ }^{b} p<0.05$ compared with the diabetic control group. ${ }^{c} p<0.05$ compared with the diabetic animals received Sitagliptin. Results are expressed as mean + SEM (standard error of mean), one-way ANOVA and post-hoc LSD test. E.C.: Eryngium caucasicm; FBS: fasting blood glucose; MDA: malondialdehyde; TAC: total antioxidant capacity; hs-CRP: high sensitivity C-reactive protein; IL-6: interleukin-6. 


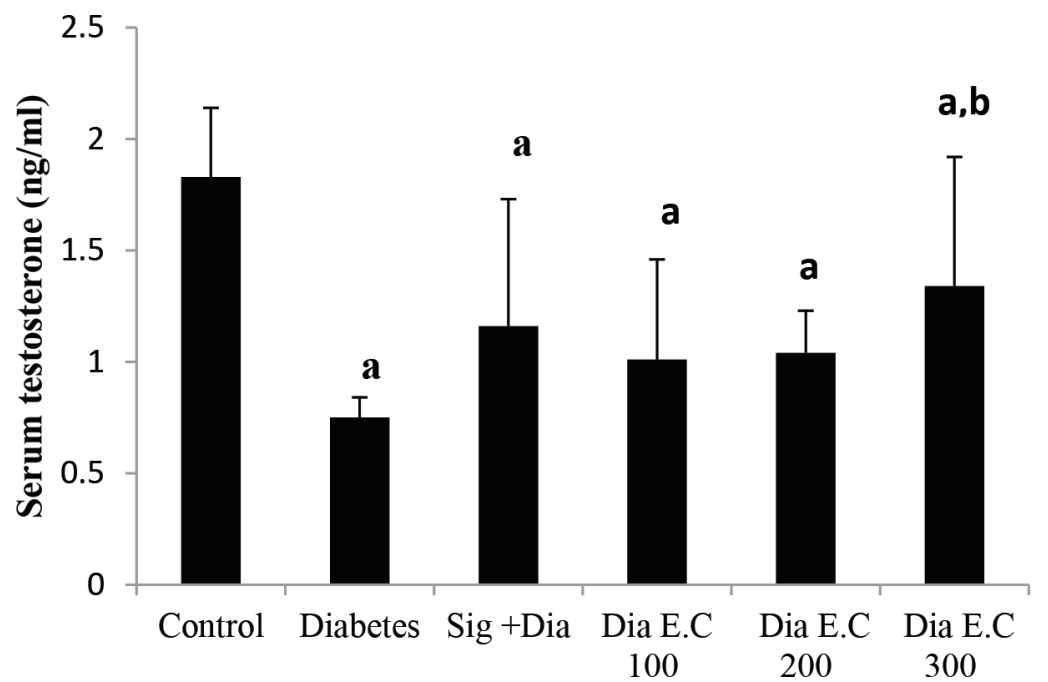

Fig. 1 Effect of hydro-alcoholic extract of Eryngium caucasicm (E.C.) on testosterone serum level in nicotinamide-streptozotocininduced diabetic Wistar rats. Values outlined as Mean (SEM; standard error of mean), One-way ANOVA and post-hoc LSD test. Dia: Diabetic, E.C.: Eryngium caucasicm, Sig: sitagliptin, 100: $100 \mathrm{mg} / \mathrm{kg}$ hydro-alcoholic extract E.C., 200: 200 $\mathrm{mg} / \mathrm{kg}$ hydro-alcoholic extract E.C., 300: $300 \mathrm{mg} /$ kg hydro-alcoholic extract E.C. ${ }^{a} P<0.05$ compared with the control group, ${ }^{b} P<0.05$ compared with the diabetic control group. species reported to contain several phenolic compounds, flavonoids and coumarins which their antioxidant activities have been documented. ${ }^{25}$ Because of high polyphenols and flavonoids contents of E. caucasicum extract, their efficient $\mathrm{NO}$ scavenging activities have been reported. ${ }^{23}$ Lipid peroxidation marker, MDA, in our study significantly decreased in dosedependent manner; the effect on NO production could be one of possible mechanisms. The correlation between total phenolic contents and antioxidant activity has been widely studied. The important point is that the NO scavenging effect was mostly dose-dependent in previous studies. ${ }^{16}$ We also found almost dose-dependent effect regarding antioxidant activity of E. caucasicum in diabetic rats.

We showed anti-inflammatory effects of E. caucasicum extract in diabetic rats. IL- 6 and hs-CRP both decreased in all doses of E. caucasicum. These findings were in agreement with findings of Dawilai et al. ${ }^{26}$ and Jaghabir ${ }^{27}$ in which antiinflammatory effects of E. caucasicum extract were reported.

Alteration in serum vitamin B12 could be due to hepatic injury in diabetic rats. ${ }^{28}$ Previous studies in humans reported lowered serum B12 in diabetes; ${ }^{29}$ although E. caucasicum due to its antioxidant effects could be hepato-protective, serum vitamin B12 could be lost via urine which has not examined in this study. Our study did not show any significant effect in serum vitamin B12.

Effects of Eryngium species (especially roots) against different inflammatory disorders are recognized in the traditional medicines worldwide; for instance, Eryngium campestre as anti-edema ${ }^{30}$ or Eryngium creticum for inflammatory wound ${ }^{31}$ or against kidney and urinary tract inflammations and edema. ${ }^{32}$ Despite widespread uses of Eryngium species in the treatment of inflammatory disorders worldwide, the number of scientific papers investigating the anti-inflammatory activity potential are scarse; like Eryngium yuccifolium aerial parts, ${ }^{33}$ Eryngium maritimum rhizomes, ${ }^{34}$ Eryngium bilardieri aerial parts and roots, ${ }^{35}$ Eryngium foetidum leaves. ${ }^{36}$ Ethanol and water extract of roots and aerial parts of eight Eryngium species were investigated for their inhibitory effects on several inflammatory models in mice. Results showed different degrees of anti-inflammatory activity for Eryngium species. ${ }^{17}$ A significant anti-inflammatory activity was reported in the n-butanol extract E. billardieri, which mainly contains saponins. ${ }^{35}$ The myeloperoxidase activity as a marker of polymorphonuclear cells migration to the inflamed tissues reported to be reduced strongly after E. foetidum extract administration. ${ }^{37} \mathrm{NO}$ is also implicated in inflammation ${ }^{38}$ and as mentioned recently, E. caucasicum showed anti-scavenging effect against NO. Interestingly $E$. foetidum leaves extract showed a significant and dose-dependent anti-inflammatory activity, orally against carrageenan-induced rat paw edema. ${ }^{39}$ Here, we showed dose-dependent anti-inflammatory effects of E. caucasicum in diabetic rats. Additionally, hs-CRP and IL-6 decreased significantly in a dose-dependent manner.

Administration of E. caucasicum extract improved testosterone serum level only in the highest doses of E. caucasicum extract. Reduced serum testosterone level reported in diabetic rats due to reduced amount and functioning of Leydig cells ${ }^{40}$ and also absence of normal serum insulin levels because, insulin plays a positive role in Leydig cell function and testosterone production. ${ }^{41}$ Furthermore, inhibition of steroidogenesis because of elevated inflammatory biomarkers and reduction in the activity of antioxidant enzymes also has been implicated. $^{42}$ We showed that E. caucasicum significantly improved serum testosterone level. Since insulin acts as an anti-apoptotic factor which is able to regulate testicular apoptosis; thus reduction in insulin serum levels leads to reduced testosterone serum level. Insulin secretary effects of $E$. caucasicum extract could improve testosterone levels in treated groups. Another probable mechanism is that increasing of ROS and oxidative stress can prevent production of androgens. ${ }^{43}$ The protective effects of E. caucasicum extract could be due to antioxidant and anti-inflammatory effects. Some researchers also suggested that flavonoids and saponins have positive effects on androgen production and bioavailability. Saponins increase testosterone generation through influencing on pituitary leuteizing hormone secretion on Leydig cells. ${ }^{44}$ Therefore, it can be inferred that observed effects of E. caucasicum extract on serum testosterone levels are related to the presence of these compounds.

\section{Conclusion}

In conclusion, we showed that administration of E. caucasicum in T2DM animal model has antioxidant and anti-inflammatory effects. E. caucasicum decreased serum IL-6, MDA and hs-CRP and also increased TAC. Highest doses of E. caucasicum 
also improved testosterone serum level. On the whole, it seems that E. caucasicum influences on inflammation and oxidative stress in diabetes rat fellow a dose-dependent manner, although higher doses showed better effects. However, in future studies other dose-escalating intervention must be performed; in which higher doses evaluated to clarify the exact dose-response effects of eryngo. Also toxicity in diabetes must be elucidated in future studies.

\section{Conflict of Interest}

\section{None.}

\section{References}

1. DeFronzo RA, Ferrannini E, Groop L, Henry RR, Herman WH, Holst JJ, et al. Type 2 diabetes mellitus. Nat Rev Dis Primers. 2015;1:15019.

2. Centers for Disease Control and Prevention. National diabetes statistics report, 2017. Atlanta, GA: Centers for Disease Control and Prevention, 2017.

3. Zhang P, Zhang X, Brown J, Vistisen D, Sicree R, Shaw J, et al. Global healthcare expenditure on diabetes for 2010 and 2030. Diabetes Res Clin Pract. 2010:87:293-301.

4. Chan GC, Tang SC. Diabetic nephropathy: landmark clinical trials and tribulations. Nephrol Dial Transplant. 2015:31:359-368.

5. Akash MS, Rehman K, Chen S. Role of inflammatory mechanisms in pathogenesis of type 2 diabetes mellitus. J Cell Biochem. 2013;114:525-531.

6. Pradhan AD, Manson JE, Rifai N, Buring JE, Ridker PM. C-reactive protein, interleukin 6, and risk of developing type 2 diabetes mellitus. JAMA. 2001;286:327-334

7. Donath MY, Dalmas É, Sauter NS, Böni-Schnetzler M. Inflammation in obesity and diabetes: islet dysfunction and therapeutic opportunity. Cell Metab. 2013;17:860-872.

8. Kitamura T. The role of FOXO1 in $\beta$-cell failure and type 2 diabetes mellitus Nat Rev Endocrinol. 2013;9:615-623.

9. Ghorbani A. Best herbs for managing diabetes: a review of clinical studies. Braz J Pharm Sci. 2013;49:413-422.

10. Rao MU, Sreenivasulu M, Chengaiah B, Reddy KJ, Chetty CM. Herbal medicines for diabetes mellitus: a review. Int J PharmTech Res. 2010;2:1883-1892.

11. Ji HF, Li XJ, Zhang HY. Natural products and drug discovery: can thousands of years of ancient medical knowledge lead us to new and powerful drug combinations in the fight against cancer and dementia? EMBO Rep. 2009:10:194-200.

12. Calviño Cl, Martínez SG, Downie SR. The evolutionary history of Eryngium (Apiaceae, Saniculoideae): rapid radiations, long distance dispersals, and hybridizations. Mol Phylogenet Evol. 2008;46:1129-50.

13. Nabavi SM, Nabavi SF, Alinezhad H, Zare M, Azimi R. Biological activities of flavonoid-rich fraction of Eryngium caucasicum Trautv. Eur Rev Med Pharmacol Sci. 2012;16:81-87.

14. Wörz A. On the distribution and relationships of the South-West Asian species of Eryngium L. (Apiaceae-Saniculoideae). Turk J Bot. 2004;28:85-92.

15. Trautv P. Plants for a future, edible, medicinal and useful plants for a healthier world, Eryngium caucasicum. 2004.

16. Motallebi Riekandeh S, Mazandarani M, Ebrahimzadeh MA, Zargari M. Antioxidant activities of Eryngium caucasicum inflorescence. Eur Rev Med Pharmacol Sci. 2016;20:946-949.

17. Küpeli E, Kartal M, Aslan S, Yesilada E. Comparative evaluation of the antiinflammatory and antinociceptive activity of Turkish Eryngium species. J Ethnopharmacol. 2006;107:32-37.

18. Wang P, Su Z, Yuan W, Deng G, Li S. Phytochemical constituents and pharmacological activities of Eryngium L. (Apiaceae). 2012:3:99-120.

19. Ben Lajnef H, Ferioli F, Pasini F, Politowicz J, Khaldi A, Filippo D'Antuono L, et al. Chemical composition and antioxidant activity of the volatile fraction extracted from air-dried fruits of Tunisian Eryngium maritimum L. ecotypes. J Sci Food Agric. 2018;98:635-643.

20. Marčetić MD, Petrović SD, Milenković MT, Niketić MS. Composition, antimicrobial and antioxidant activity of the extracts of Eryngium palmatum Pančić and Vis. (Apiaceae). Central Eur J Biol. 2014;9:149-155.

21. Erdem SA, Nabavi SF, Orhan IE, Daglia M, Izadi M, Nabavi SM. Blessings in disguise: a review of phytochemical composition and antimicrobial activity of plants belonging to the genus Eryngium. Daru. 2015;23:53.

22. Merghache D, Boucherit-Otmani Z, Merghache S, Chikhi I, Selles C, Boucherit K. Chemical composition, antibacterial, antifungal and antioxidant activities of Algerian Eryngium tricuspidatum L. essential oil. Nat Prod Res. 2014;28:795-807.
23. Khalili M, Dehdar T, Hamedi F, Ebrahimzadeh MA, Karami M. Antihypoxic activities of Eryngium caucasicum and Urtica dioica. Eur Rev Med Pharmacol Sci. 2015;19:3282-3285.

24. Ebrahimzadeh MA, Nabavi SF, Nabavi SM, Pourmorad F. Nitric oxide radical scavenging potential of some Elburz medicinal plants. Afr J Biotechnol. 2010;9:5212-5217.

25. Rjeibi I, Saad AB, Ncib S, Souid S. Phenolic composition and antioxidant properties of Eryngium maritimum (sea holly). J Coast Life Med. 2017;5:212-215.

26. Dawilai S, Muangnoi C, Praengamthanachoti P, Tuntipopipat S. Antiinflammatory activity of bioaccessible fraction from Eryngium foetidum leaves. Biomed Res Int. 2013;2013:958567.

27. Jaghabir M. Hypoglycemic effects of Eryngium creticum. Arch Pharm Res 1991;14:295-297.

28. Afrin R, Arumugam S, Soetikno V, Thandavarayan R, Pitchaimani V, Karuppagounder $V$, et al. Curcumin ameliorates streptozotocin-induced liver damage through modulation of endoplasmic reticulum stress-mediated apoptosis in diabetic rats. Free Radic Res. 2015;49:279-289.

29. Akinlade KS, Agbebaku SO, Rahamon SK, Balogun WO. Vitamin B12 levels in patients with type 2 diabetes mellitus on metformin. Ann Ib Postgrad Med. 2015;13:79-83.

30. Leporatti ML, Ivancheva S. Preliminary comparative analysis of medicinal plants used in the traditional medicine of Bulgaria and Italy. J Ethnopharmacol. 2003;87:123-142.

31. Ali-Shtayeh MS, Yaghmour RM, Faidi YR, Salem K, Al-Nuri MA. Antimicrobial activity of 20 plants used in folkloric medicine in the Palestinian area. J Ethnopharmacol. 1998;60:265-271.

32. Gruenwald J, Brendler T, Jaenicke C. PDR for Herbal Medicines. Thomson Reuters Corporation. 2007

33. Benoit PS, Fong HH, Svoboda GH, Farmsworth NR. Biological and phytochemical evaluation of plants. XIV. Antiinflammatory evaluation of 163 species of plants. Lloydia. 1976;39:160-171.

34. Lisciani R, Fattorusso E, Surano V, Cozzolino S, Giannattasio M, Sorrentino L. Anti-inflammatory activity of Eryngium maritimum L. rhizome extracts in intact rats. J Ethnopharmacol. 1984;12:263-270.

35. Yesilada E, Tanaka S, Tabata M, Sezik E. The antiinflammatory activity of the fractions from Eryngium billardieri in mice. Phytother Res. 1989;3:38-40.

36. García MD, Sáenz MT, Gómez MA, Fernández MA. Topical antiinflammatory activity of phytosterols isolated from Eryngium foetidum on chronic and acute inflammation models. Phytother Res. 1999;13:78-80.

37. Mekhora C, Muangnoi C, Chingsuwanrote P, Dawilai S, Svasti S, Chasri K, et al. Eryngium foetidum suppresses inflammatory mediators produced by macrophages. Asian Pac J Cancer Prev. 2012;13:653-664.

38. Nabavi SM, Ebrahimzadeh MA, Nabavi SF, Bahramian F. In vitro antioxidant activity of Phytolacca americana berries. Pharmacologyonline. 2009;1:81-88.

39. Sáenz MT, Fernández MA, Garcia MD. Antiinflammatory and analgesic properties from leaves of Eryngium foetidum L. (Apiaceae). Phytother Res. 1997;11:380-383.

40. Khaneshi F, Nasrolahi O, Azizi S, Nejati V. Sesame effects on testicular damage in streptozotocin-induced diabetes rats. Avicenna J Phytomed. 2013;3:347-355.

41. Lin T, Haskell J, Vinson N, Terracio L. Characterization of insulin and insulinlike growth factor I receptors of purified Leydig cells and their role in steroidogenesis in primary culture: a comparative study. Endocrinology. 1986:119:1641-1647.

42. Kalyani RR, Dobs AS. Androgen deficiency, diabetes, and the metabolic syndrome in men. Curr Opin Endocrinol Diabetes Obes. 2007;14:226-234.

43. Zhao YT, Qi YW, Hu CY, Chen SH, Liu Y. Advanced glycation end products inhibit testosterone secretion by rat Leydig cells by inducing oxidative stress and endoplasmic reticulum stress. Int J Mol Med. 2016;38:659-665.

44. Rojas DP, Pandey AK. Natural compounds to counteract testosterone depletion in aging. J Steroids Horm Sci. 2014;5:e112

This work is licensed under a Creative Commons Attribution-NonCommercial 3.0 Unported License which allows users to read, copy, distribute and make derivative works for non-commercial purposes from the material, as long as the author of the original work is cited properly. 